\title{
Distribusi Coulomb Stress Akibat Gempabumi Tektonik Selatan Pulau Jawa berdasarkan Data Gempa Tektonik 1977-2000
}

\author{
Fitri Puspasari $^{1, *}$ dan Wahyudi ${ }^{2}$ \\ ${ }^{1}$ Departemen Teknik Elektro dan Informatika Sekolah Vokasi, Universitas Gadjah Mada, Yogyakarta, 55281 \\ ${ }^{2}$ Jurusan Fisika, Fakultas Matematika dan Ilmu Pengetahuan Alam, Universitas Gadjah Mada, Yogyakarta, 55281
}

Intisari

Telah dilakukan penelitian untuk menghitung distribusi Coulomb stress dengan menggunakan software Coulomb 3.3. Peningkatan nilai perubahan Coulomb stress mengindikasikan adanya akumulasi stress pada batuan. Data penelitian diambil dari katalog ISC (International Seismological Center) dan Global CMT (Global Centroid Moment Tensor). Hasil pengolahan data adalah terjadi peningkatan Coulomb stress di kawasan selatan pulau Jawa dengan kisaran nilai 0,01-1 kPa dan diduga dapat menimbulkan terjadinya akumulasi stress akibat gempabumi tektonik yang mengarah ke bawah puncak gunungapi Merapi.

\begin{abstract}
This study has been applied to calculate Coulomb stress distribution using Coulomb 3.3 software. Increasing the value of Coulomb stress changes indicated accumulation of stress on rocks. The data is taken from the catalog of ISC (International Seismological Center) and Global CMT (Global Centroid Moment Tensor). The results of data processing is an increase in Coulomb stress in the South of Java Island with a ranges $0.01-1 \mathrm{kPa}$ and allegedly caused the accumulation of stress due to tectonic earthquake that leads to the volcano.
\end{abstract}

KATA KUNCI: Gempabumi tektonik, perubahan Coulomb stress, sesar. http://dx.doi.org/10.12962/j24604682.

\section{PENDAHULUAN}

Indonesia memiliki gunungapi terbanyak di dunia, di antaranya 129 gunungapi masih dalam kondisi aktif. Banyaknya gunungapi di Indonesia merupakan dampak dari kompleksnya tatanan tektonik yang ada di Indonesia yaitu terdiri dari lem-

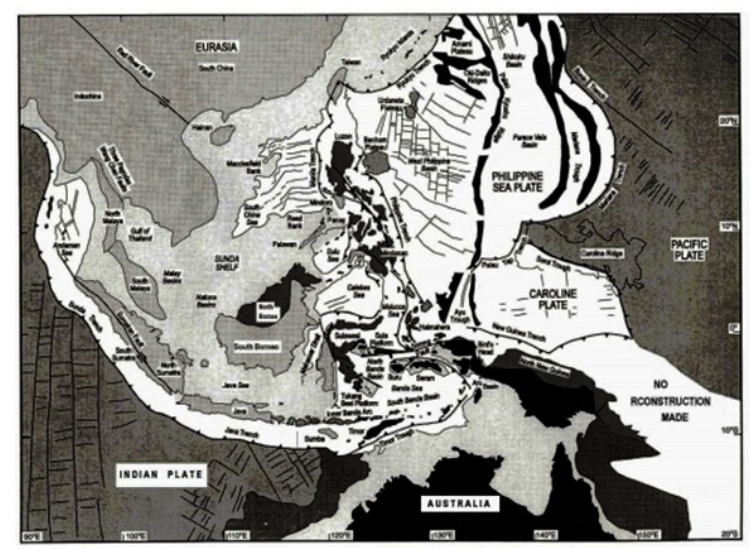

Gambar 1: Peta tektonik Indonesia [2]

\footnotetext{
*E-MAIL: fitri.puspasari@ugm.ac.id
}

peng India-Australia, lempeng Eurasia dan lempeng Pasifik, sebagaimana ditunjukkan pada Gambar $1[1,2]$.

Jika mengamati peta vulkanisme global, tampak bahwa jalur sabuk gunungapi dunia berdampingan dengan jalur gempabumi. Fenomena meningkatnya aktivitas gunungapi didahului aktivitas kumulatif gempabumi tektonik di kawasan selatan pulau Jawa [3].

Mekanisme gempabumi tektonik berhubungan dengan distribusi tegangan statis yang terjadi pada batuan. Beberapa peneliti terdahulu mencoba menghitung perubahan Coulomb stress yang nampaknya menjadi dasar korelasi antara aktivitas gunungapi dengan gempabumi tektonik.

Penelitian yang terkait dengan hubungan gempabumi dan gunungapi dilakukan oleh Walter, et al. [4] yang menyelidiki tentang hubungan antara erupsi Merapi 2001 dan 2006 dengan peristiwa gempabumi tektonik yang terjadi sebelumnya. Hasil pengamatan yaitu terjadinya gempabumi tektonik di sekitar Merapi terbukti telah meningkatkan ekstrusi magma dan guguran material piroklastik Merapi.

Berdasarkan uraian di atas, penelitian ini bertujuan untuk mengetahui distribusi perubahan Coulomb stress di kawasan selatan pulau Jawa dengan mengamati kejadian-kejadian aktivitas seismik di sekitar gunungapi Merapi.

\section{Geologi daerah penelitian}

Gunungapi Merapi terletak di propinsi Daerah Istimewa Yogyakarta dan propinsi Jawa Tengah, tepatnya pada koordinat $7,53^{\circ}$ LS dan $110,43^{\circ}$ BT dengan ketinggian 2.968 


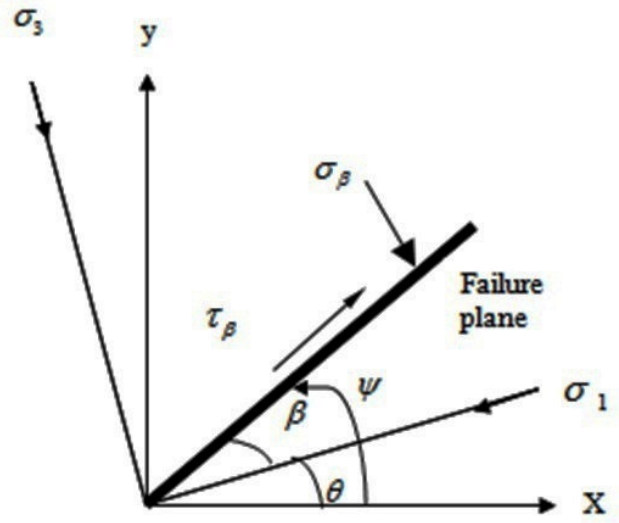

Gambar 2: Sistem koordinat untuk kalkulasi stress pada bidang patahan optimum [6].

$\mathrm{m}$ di atas permukaan laut. Kawasan gunungapi Merapi dan sekitarnya terletak di zona subduksi, sehingga termasuk bagian dari sistem tektonik Indonesia dengan tingkat aktivitas kegempaan tinggi.

Kondisi geologi gunungapi Merapi yaitu terdiri dari batuan gunung Merapi Muda dan Merapi Tua. Gunungapi Merapi merupakan salah satu hasil rangkaian proses vulkanik di pertengahan pulau Jawa yang terletak pada perpotongan dua sesar regional yaitu transverse fault dan longitudinal fault. Transverse fault ini memisahkan Jawa Timur dan Jawa Tengah, sedangkan longitudinal fault dibatasi oleh Kendeng Ridge dan subzone Ngawi. Pada zona transverse fault, Gunung Merapi terletak pada kelurusan jajaran gunungapi, mulai dari Ungaran, Soropati-Telomoyo, Merbabu dan Merapi berurutan dari Utara ke Selatan [5].

\section{Perubahan Coulomb Stress}

Model yang banyak digunakan untuk menjelaskan interaksi patahan adalah perubahan tegangan Coulomb (Coulomb stress change). Dengan mengasumsikan model gesek Coulomb sederhana (simple coulomb friction model) untuk gempabumi, slip potensial akan meningkat atau menurun pada Coulomb failure stress, dan didefinisikan sebagai:

$$
\sigma_{f}=\tau_{\beta}-\mu\left(\mu_{\beta}-p\right)
$$

dengan $\sigma_{f}$ adalah Coulomb failure, $\tau_{\beta}$ adalah shear stress, $\sigma_{\beta}$ adalah normal stress, $\mathrm{p}$ adalah tekanan pori (pore fluid pressure) dan $\mu$ adalah koefisien gesek. Slip potensial yang mengarah kekanan atau kekiri. Nilai dari $\sigma$ dalam hal ini harus selalu positif, namun sebaliknya proses yang berlangsung dalam mencari nilai stress kepatahan dapat dihasilkan nilai positif maupun negatif bergantung pada slip potensial mengarah kekanan atau kekiri.

Sistem koordinat pada Gambar 2 menunjukkan bidang patahan (failure plane) yang dikenakan normal stress $\sigma_{\beta}$ atau disebut komponen stress utama dan $\tau_{\beta}$ adalah shear stress atau komponen stress geser pada bidang patahan [7].
TABEL I: Parameter mekanisme fokus Gempabumi tektonik tahun 1977-2000 (http://www.globalcmt.org).

\begin{tabular}{llllllllll}
\hline \hline Event & Lat & Lon & \multicolumn{2}{c}{ Depth Strike1; Dip 1; Slip 1; } & $\mathrm{Mw}$ \\
& & & & strike 2 & Dip 2 & Slip 2 & \\
\hline $1977 / 8 / 14$ & -8.73 & 107.10 & 33.0 & $291 ; 95$ & $24 ; 67$ & $105 ; 84$ & 6.1 \\
$1979 / 11 / 2$ & -7.98 & 108.52 & 72.2 & $20 ; 223$ & $41 ; 51$ & $72 ; 105$ & 6.5 \\
$1980 / 4 / 16$ & -8.24 & 108.64 & 85.2 & $11 ; 233$ & $40 ; 58$ & $55 ; 116$ & 6.1 \\
$1981 / 3 / 13$ & -8.62 & 110.15 & 48.6 & $139 ; 275$ & $11 ; 82$ & $-47 ;-98$ & 5.9 \\
$1983 / 8 / 13$ & -8.95 & 111.60 & 65.8 & $260 ; 94$ & $36 ; 55$ & $78 ; 98$ & 5.8 \\
$1983 / 8 / 17$ & -9.02 & 111.68 & 67.0 & $282 ; 68$ & $43 ; 52$ & $116 ; 68$ & 5.5 \\
$1984 / 5 / 3$ & -8.79 & 111.14 & 73.9 & $258 ; 109$ & $33 ; 61$ & $64 ; 106$ & 5.4 \\
$1992 / 11 / 21$ & -9.28 & 110.29 & 35.4 & $321 ; 91$ & $26 ; 73$ & $137 ; 71$ & 5.5 \\
$1995 / 5 / 5$ & -9.81 & 110.42 & 44.4 & $292 ; 128$ & $34 ; 57$ & $137 ; 71$ & 5.4 \\
$1996 / 9 / 25$ & -9.74 & 108.32 & 38.8 & $141 ; 245$ & $58 ; 69$ & $155 ; 34$ & 5.6 \\
$1996 / 12 / 9$ & -8.32 & 107.44 & 46.5 & $297 ; 99$ & $29 ; 63$ & $107 ; 81$ & 6.0 \\
$1997 / 7 / 12$ & -9.24 & 110.31 & 50.2 & $267 ; 125$ & $35 ; 61$ & $57 ; 111$ & 5.3 \\
$1999 / 3 / 27$ & -9.79 & 112.96 & 29,9 & 136,348 & $21 ; 72$ & $120 ;-79$ & 5.5 \\
$2000 / 1 / 5$ & -9.39 & 109.59 & 22 & $294 ; 99$ & $20 ; 70$ & $104 ; 85$ & 5.8 \\
\hline \hline
\end{tabular}

Pers.(1) selanjutnya dapat ditulis dengan asumsi bahwa $\sigma_{\beta}$ mewakili batasan stress seperti stress normal pada bidang.

$$
\Delta \sigma_{f}=\Delta \tau_{\beta}-\mu^{\prime} \Delta \sigma_{\beta}
$$

Koefisien gesek efektif $(\mu)$ dinyatakan dengan $\mu^{\prime}=\mu(1-\mathrm{B})$. Selanjutnya jika $\sigma_{f}>0$ potensial slip akan meningkat dan jika $\sigma_{f}<0$ potensial slip akan berkurang. Kalkulasi yang disebabkan oleh gempabumi bergantung kepada geometri dan distribusi slip, asumsi magnitudo, orientasi stress regional serta nilai dari asumsi koefisien gesek. Rasio dari amplitude stress regional terhadap stress drop gempabumi hanya berdampak signifikan di dekat patahan. Ketidakpastian dalam beberapa kejadian selalu didominasi oleh ketidakpastian distribusi slip [6].

\section{METODE PENELITIAN}

Penelitian ini mengambil data gempa kawasan Gunungapi Merapi dan sekitarnya dengan letak koordinat $107-113^{\circ} \mathrm{BT}$ dan $-11-4^{\circ}$ LS. Data yang digunakan berupa data kejadian gempa bumi tahun 1977 -2000 ( Tabel I) yang diperoleh dari katalog gempa bumi Global CMT (Global Centroid Moment Tensor) dan ISC (International Seismological Center).

Data mekanisme sumber yang didapat dari katalog ISC, Global CMT, dan USGS/NEIC terdapat data lattitude, longitude, dan parameter sesar seperti strike, dip, rake. Data yang telah diunduh dibuka dengan program notepad++ kemudian dicopy ke dalam software microsoft excel sesuai kebutuhan dalam data input software selanjutnya yang akan digunakan. Hasil unduhan dari ISC, GCMT dan USGS disimpan dalam bentuk .txt (notepad++) dan .xls (microsoft excel).

Pada pengolahan mekanisme sumber, data yang digunakan adalah data gempabumi tektonik dari tahun 1977 sampai 2000, diambil dari katalog gempabumi yaitu ISC. Plotting dilakukan dengan menggunakan software Generic Mapping Tools (GMT), hasil keluaran software ini berupa penyelesaian mekanisme yang ditampilkan sebagai beachball. 


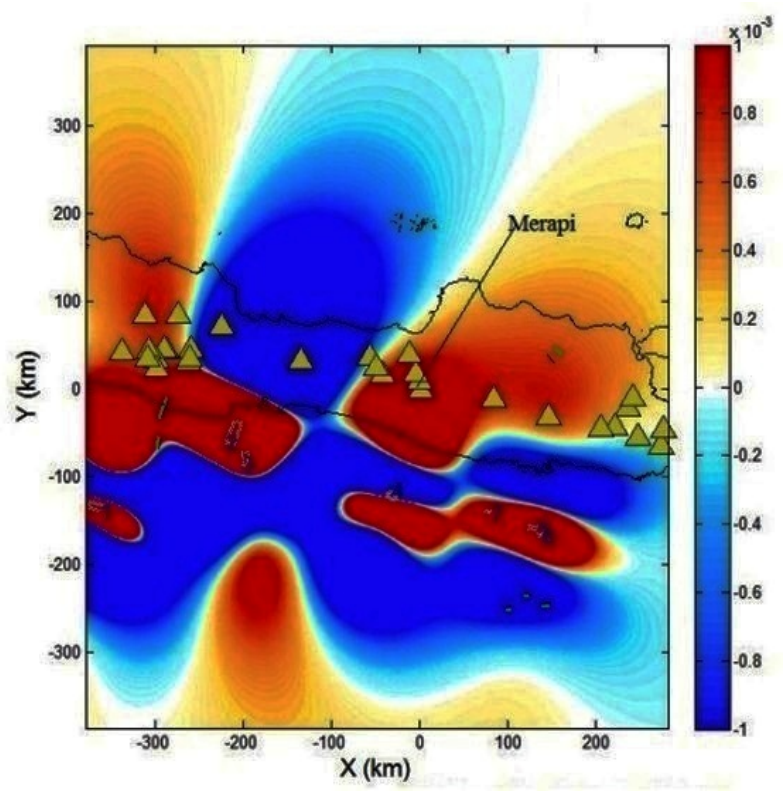

(a)periode tahun 1977-1984

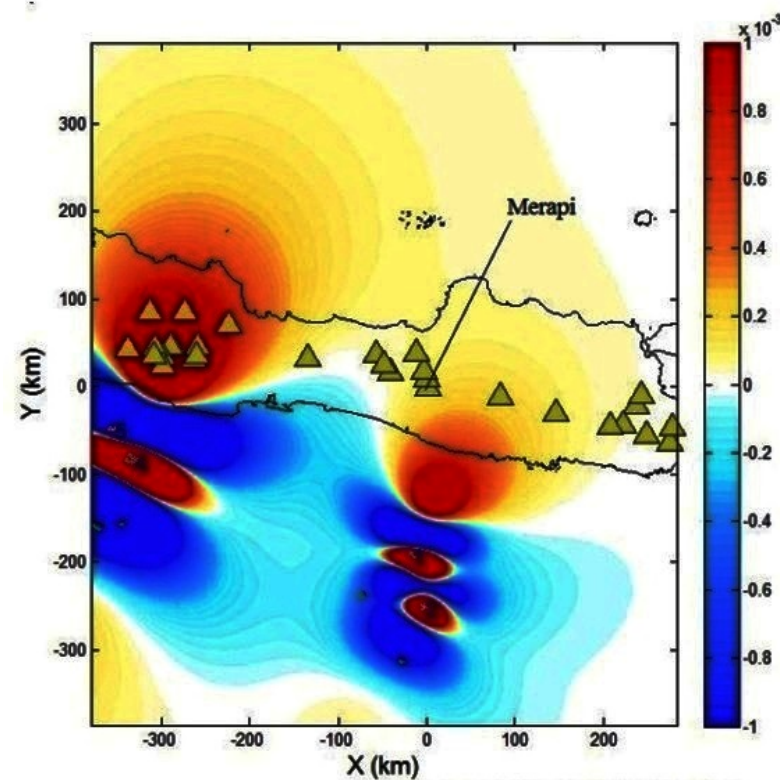

(b)periode tahun 1992-1998

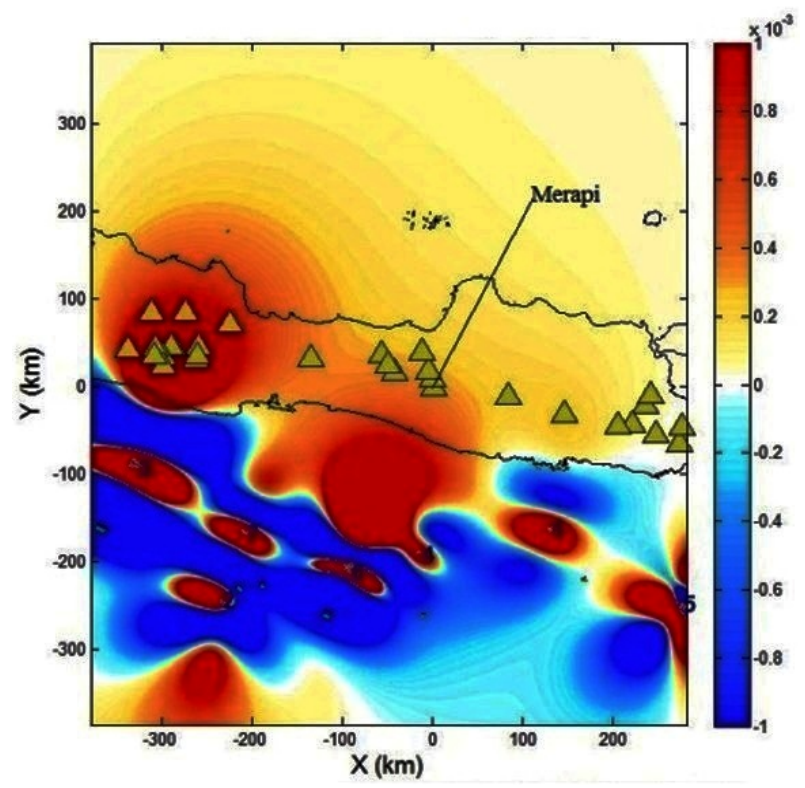

(c)periode tahun 1995-2001

Gambar 3: Coulomb stress change gempabumi

Berdasarkan model bidang patahan dari mekanisme fokal dalam bentuk beachball, akan terlihat jelas tipe patahan yang menyebabkan gempabumi itu terjadi antara lain sesar naik, sesar turun, dan sesar geser. Sesar yang tergambar pada bola fokus tersebut menggambarkan rekahan yang mengalami geseran-geseran yang jelas yang merupakan penyebab terjadinya gempabumi.

Setelah sebaran bola fokal dipetakan, karakteristik sesar dapat ditentukan, kemudian distribusi Coulomb stress statis dapat dihitung dengan menggunakan software Coloumb 3.3. Data masukan yang akan digunakan pada software ini adalah data gempabumi tektonik yang diambil dari katalog gempabumi Global CMT. Hasil akhir dari perhitungan perubahan tegangan statis (coulomb stress) ini adalah berupa distribusi nilai perubahan stress statis.

\section{HASIL DAN PEMBAHASAN}

Solusi mekanisme sumber dari katalog Global CMT tepatnya pada koordinat -11 sampai -6 LS dan 105 sampai 115 . Sebagian besar gempabumi tektonik terjadi di bagian sela- 
tan Pulau Jawa. Hasil pemetaan mekanisme sumber menunjukkan bahwa selatan pulau Jawa didominasi oleh jenis sesar naik sedikit geser.

Analisis hasil perhitungan distribusi Coulomb stress menggunakan parameter mekanisme sumber gempabumi vulkanotektonik sebagai receiver fault dari peneliti terdahulu [8].

Gambar 3 menunjukkan salah satu hasil perhitungan Coulomb stress gempabumi tektonik 19772000 terhadap receiver fault gempabumi VTA.

Hasil perhitungan perubahan Coulomb stress pada Gambar 3(a) menunjukkan daerah yang mengalami peningkatan stress ditunjukkan oleh nilai Coulomb stress positif warna orange hingga merah dari sumber gempabumi kemudian melemah menuju kawasan gunungapi Merapi sebagaimana ditunjukkan pada gambar kisaran nilai Coulomb stress positif ini adalah 0,0001 bar hingga 0,001 bar atau setara $0,01 \mathrm{kPa} 1 \mathrm{kPa}$.

Kemudian pada Gambar 3(b) dapat dilihat bahwa hanya beberapa sumber gempabumi yang distribusi nilai stressnya mengarah kekawasan gunungapi Merapi dengan kisaran nilai Coulomb stress positif ini adalah 0,001 bar melemah hingga 0,0002 bar.

Pada awal tahun 2001, gejala peningkatan aktivitas gunungapi mulai tampak jelas terutama di tunjukkan oleh meningkatnya jumlah guguran lava yang terekam oleh seis- mograf maupun terlihat secara visual. Pada 5 Januari 2001, status aktivitas gunungapi Merapi dinaikkan dari waspada menjadi Siaga.

Berdasarkan Gambar 3(c) dapat ditunjukkan bahwa daerah di kawasan gunungapi Merapi mengalami penurunan nilai Coulomb stress ditunjukkan dengan merah hingga memudar pada warna orange dan putih. Daerah peningkatan nilai Coulomb stress dominan terletak pada arah baratdayatimurlaut yaitu terjadi peningkatan nilai Coulomb stress dari sumber gempabumi kemudian melemah menuju Kawasan Gunungapi Merapi. Kisaran nilai Coulomb stress positif ini adalah 0,001 bar melemah hingga 0,0001 bar atau setara 0,01 $\mathrm{kPa} 1 \mathrm{kPa}$.

\section{SIMPULAN}

Kesimpulan dari penelitian ini adalah terdapat peningkatan nilai distribusi perubahan Coulomb stress yang bersumber dari gempabumi tektonik dengan skala magnitude $>5 \mathrm{Mw}$. Berdasarkan hasil perhitungan, nilai distribusi perubahan Coulomb stress mengalami peningkatan $0,01 \quad 1 \mathrm{kPa}$ dengan arah ke posisi bawah puncak gunungapi Merapi.
[1] Rosmiyatin dan AbdulBasid, Jurnal Neutrino, 4(2), 188-200 (2012).

[2] R. Hall, Plate Tectonic Reconstructions of the Indonesian Region, Proceedings Indonesian Petroleum Association, 1, 70-84 (1995).

[3] Daryono, Aktivitas Gempabumi Tektonik Di Yogyakarta Menjelang Erupsi Merapi 2010 (Badan Meteorologi Klimatologi dan Geofisika, 2010).

[4] T.R. Walter, et al., Geoph. Research Leters, 34, L05304 (2007).

[5] R.W. Van Bemmelen, The geology of Indonesia: The Hague,
Sole Agent Mart. Nijhoff (1949).

[6] G.C.P. King, R.S. Stein, and J. Lin, Bull. Seismol. Soc. Am., 84, 935-953 (1994).

[7] S. Ardiansyah, SIMETRI, 2(1), 2102-10 (2014).

[8] S. Hidayati, et al., Indonesian Journal of Physics, 19(03) 75-82 (2008).

[9] Ratdomopurbo, Subandriyo, Sulistyo, Y. Suharna, Prekursor Erupsi Gunungapi Merapi (Pusat Vulkanologi dan Mitigasi Bencana Geologi (PVMBG), 2006). 